\title{
Progression of inflammation during immunodeficient mouse skeletal muscle regeneration
}

\author{
Iwona Grabowska $^{1}$ - Magdalena A. Mazur ${ }^{1}$ - K. Kowalski ${ }^{1}$ A. Helinska ${ }^{1}$ \\ Jerzy Moraczewski ${ }^{1}$ - Władysława Stremińska ${ }^{1}$ - Grażyna Hoser ${ }^{2} \cdot$ \\ Jerzy Kawiak $^{2} \cdot$ Maria A. Ciemerych ${ }^{1}$ Edyta Brzoska ${ }^{1}$
}

Received: 30 June 2015/Accepted: 18 November 2015/Published online: 27 November 2015

(C) The Author(s) 2015. This article is published with open access at Springerlink.com

\begin{abstract}
The skeletal muscle injury triggers the inflammatory response which is crucial for damaged muscle fiber degradation and satellite cell activation. Immunodeficient mice are often used as a model to study the myogenic potential of transplanted human stem cells. Therefore, it is crucial to elucidate whether such model truly reflects processes occurring under physiological conditions. To answer this question we compared skeletal muscle regeneration of $\mathrm{BALB} / \mathrm{c}$, i.e. animals producing all types of inflammatory cells, and SCID mice. Results of our study documented that initial stages of muscles regeneration in both strains of mice were comparable. However, lower number of mononucleated cells was noticed in regenerating SCID mouse muscles. Significant differences in the number of CD14-/CD45+ and CD14+/CD45+ cells between BALB/ $\mathrm{c}$ and SCID muscles were also observed. In addition, we found important differences in M1 and M2 macrophage levels of BALB/c and SCID mouse muscles identified by CD68 and CD163 markers. Thus, our data show that differences in inflammatory response during muscle regeneration, were not translated into significant modifications in muscle regeneration.
\end{abstract}

Keywords Inflammation - Muscle regeneration . Immunodeficiency

Edyta Brzoska

edbrzoska@biol.uw.edu.pl

1 Department of Cytology, Faculty of Biology, University of Warsaw, Miecznikowa 1 St., 02-096 Warsaw, Poland

2 Laboratory of Flow Cytometry, Medical Center of Postgraduate Education, Marymoncka 99/103 St., 01-813 Warsaw, Poland

\section{Introduction}

Skeletal muscle regeneration relies on the differentiation of tissue specific stem cells, i.e. satellite cells (Montarras et al. 2013; Scharner and Zammit 2011). The activation of satellite cells, occurring in response to the muscle injury, is manifested by the resumption of the cell cycle and differentiation into myoblasts [reviewed in (Ciemerych et al. 2011)]. Satellite cells start to proliferate approximately $18-24 \mathrm{~h}$ after the injury. At days 3 and 4 of regeneration the proliferation of mouse satellite cells is the most intense and it decreases during next 7-10 days (Grounds and McGeachie 1987). Simultaneously, at day 4 of regeneration satellite cells-derived myoblasts fuse into myotubes and subsequently into muscle fibers which formation is almost completed within 7-10 days after the injury (Robertson et al. 1990). Newly formed myotubes either fuse with the ends of the existing myofibers or form new myofibers and finally the innervation is restored (Robertson et al. 1993). Within 14 days after the injury full restoration of muscle architecture and function is completed (Robertson et al. 1993).

Importantly, muscle injury triggers inflammatory response which plays a crucial role both in muscle fiber degeneration as well as activation and differentiation of satellite cells [reviewed in (Brzoska et al. 2011)]. In response to local vascular damage, which is inevitable during extensive muscle injury, and signals released by degenerating muscle fibers, the inflammatory cells become attracted from the bloodstream and infiltrate the injured muscle (Kharraz et al. 2013). At first, inflammatory cells infiltrate the injured area and phagocyte the damaged tissue. Next, inflammatory cells release growth factors and cytokines that activate the migration and proliferation of satellite cells, and finally, produce enzymes to 
modify the extracellular matrix (ECM) (Kharraz et al. 2013). The first population of inflammatory cells that infiltrate the injured muscle are neutrophils which arrive within $2 \mathrm{~h}$ post injury. Later their number decreases and neutrophils become undetectable 3-4 days later (Tidball 2005; Tidball and Villalta 2010). Neutrophils phagocytose damaged fibers, release the reactive oxygen species (ROS), as well as proteases and cytokines to attract monocytes (Kharraz et al. 2013; Lockhart and Brooks 2008; Pizza et al. 2001).

Muscle damage induces migrating and also resident monocytes to differentiate into macrophages. Pro-inflammatory macrophages are called M1 since they are the first population of macrophages observed after the muscle injury. They phagocytose necrotic muscle fibers, participate in antigen presentation, produce pro-inflammatory cytokines (e.g. TNF $\alpha$, IL-1 $\beta$ ), and express inducible nitric oxide synthase which allows to metabolize L-arginine to produce NO (Arnold et al. 2007). Second population of macrophages participating in skeletal muscle repair are M2 macrophages presenting anti-inflammatory activity by expressing anti-inflammatory cytokines, such as IL-10 and TGF $\beta$ (Villalta et al. 2009). Pro-inflammatory M1 cells were shown to positively influence myoblast proliferation and repress myoblast differentiation (Arnold et al. 2007). On the other hand anti-inflammatory cytokines produced by M2 cells promote myogenesis, enhance angiogenesis, and stimulate deposition of ECM components (Deng et al. 2012; Zhang et al. 2013). ECM is mainly produced by muscle resident fibroblasts that migrate to the site of injury immediately after muscle damage (Mann et al. 2011; Serrano et al. 2011). Proper remodeling of ECM in damaged muscle is critical for the reconstruction of scaffold structures required for the correct alignment of newly formed muscle fibers, and thus, for the regaining of muscle function. Incorrect ECM deposition may lead to the fibrosis of injured muscle.

Interestingly, the role of $\mathrm{T}$ cells and mast cells seems to be rather limited in muscle regeneration (Kharraz et al. 2013). Thus, $8 \mathrm{~h}$ after the injury the mast cells accumulate and release many pro-inflammatory cytokines (e.g. TNF $\alpha$, IL-1, IL-6). On the other hand, T cell-secreted cytokines that play a role in maintaining activation of macrophages and produce anti-fibrotic (IFN $\gamma, \mathrm{TNF} \alpha, \mathrm{IL}-2, \mathrm{IL}-12)$ and pro-fibrotic cytokines (IL-4, IL-5, IL-6, IL-13). Knowing that, we asked whether there are any differences in skeletal muscle regeneration of severe combined immunodeficiency (SCID) mice, i.e. animals that are characterized by the lack of the humoral and cell-mediated immunity due to the absence of mature $\mathrm{T}$ and $\mathrm{B}$ lymphocytes (Renz et al. 1996). SCID mice were derived from BALB/c C.B-17 mice (Bosma et al. 1983). They accept xenogeneic grafts and for this reason they are widely used as a model in transplantation studies (Vormoor et al. 1994). However, they are not a perfect model since they are characterized by the presence of NK cells. Thus, cyclophosphamide treatment is necessary before xenogeneic cells implantation (Basch et al. 1997). Despite this "imperfection" SCID mice are often used as a model to study myogenic potential of stem cells, including human-derived stem cells (Brzoska et al. 2006; Dellavalle et al. 2007; Grabowska et al. 2012, 2013; Morosetti et al. 2010). In this study we compared BALB/c (control) and SCID mouse skeletal muscle regeneration and inflammatory process accompanying this process.

\section{Materials and methods}

\section{Muscle injury}

All experimental procedures involving animals were approved by the Institutional Review Boards of the Medical Centre of Postgraduate Education, Warsaw. BALB/c and SCID mice were bred and maintained under defined flora conditions at the Department of Clinical Cytology, Medical Center of Postgraduate Education, Warsaw. Breeding of mice was initiated from BALB/c C.B-17-Icr Hnd Hsd SCID animals obtained from Harlan Farms, UK, and animals were frequently controlled for the absence of $\mathrm{B}$ and T lymphocytes. Males 8-10 weeks of age were used for the experiments. Animals were anesthetized with pentobarbital sodium salt (Sigma-Aldrich) by an intraperitoneal injection $(30 \mathrm{mg} / \mathrm{kg}$ of body mass). The mouse gastrocnemius muscle was crushed mechanically as previously described (Brzoska et al. 2006). Treated animals were euthanized (days $0-7$ and 30) and muscles were isolated, weighed, and processed for further analyses.

\section{Histochemistry}

The isolated gastrocnemius muscles were frozen in isopentane cooled with liquid nitrogen, transferred to $-80{ }^{\circ} \mathrm{C}$, cut into $7 \mu \mathrm{m}$ thick sections with a cryomicrotome, and stored at $4{ }^{\circ} \mathrm{C}$. Sections were hydrated and fixed in $3 \%$ PFA (paraformaldehyde) in PBS, for $10 \mathrm{~min}$. Next, sections were stained with Harris hematoxylin-eosin Y. The slides were examined with the Eclipse TE 200 microscope (Nikon Instruments, Tokyo, Japan) equipped with ACT-1 software. Sections (3-10 per each variant) were analyzed using GIMP or ImageJ to evaluate the number of mononuclear cells, muscle fiber diameter and percentage of the tissue area occupied by the connective tissue. 


\section{Cell isolation}

A single cell suspension was obtained by treatment of gastrocnemius muscle fragments with $0.15 \%$ pronase (SigmaAldrich), as described previously (Brzoska et al. 2006). Pronase is a mixture of proteases and it allows to isolate a more pure population of myogenic cells than collagenase or dispase (Danoviz and Yablonka-Reuveni 2012). Next, the cells were washed in PBS and either counted in a hemocytometer or processed for FACS analysis.

\section{FACS analysis}

The FACSCalibur (Becton-Dickinson, San Jose, CA, USA) equipped with a 488-nm argon laser was used. Four data parameters were acquired and stored: FSC, SSC, fluorescence 1-FL1 (fluorescein isothiocyanate, FITC), and fluorescence 2-FL2 (phycoerythrin, PE). CellQuest application, version 1.2, was used for the analysis. Cytometer readings were controlled systematically by Becton-Dickinson-approved service. The isolated cells were fixed in a $70 \%$ ethyl alcohol. Next, cells were washed with PBS and incubated in $2 \%$ BSA in PBS followed by anti-CD14 and CD45 antibodies (rat anti-mouse CD45 FITC conjugated clone 30-F11, monoclonal rat antimouse CD14 PE conjugated clone rmC5-3, Becton-Dickinson Bioscience). Next, cells were washed in PBS, fixed in $0.5 \%$ PFA in PBS, and subjected to FACS analysis.

\section{Immunocytochemistry}

Gastrocnemius muscles isolated at day 7 of regeneration were frozen, cut into $7 \mu \mathrm{m}$ thick sections, hydrated, and fixed in $3 \%$ PFA in PBS, for 10 min. Unspecific antibody binding was blocked by the incubation of muscle sections in $3 \% \mathrm{BSA}$ in PBS at room temperature, for $30 \mathrm{~min}$. Next, sections were incubated with antibody mix (dilution 1:50 in $3 \%$ BSA in PBS) in a humidified chamber, at room temperature, for $1 \mathrm{~h}$. Sections were incubated with FITCconjugated rat monoclonal anti-mouse CD45 or PE-conjugated rat monoclonal anti-mouse CD14 antibodies (Becton-Dickinson Bioscience) or with primary antibodies: rabbit polyclonal anti-CD68 (Abcam) and mouse monoclonal anti-CD163 (AbD Serotec), and secondary antibodies anti-mouse IgG Alexa594 conjugated (Invitrogen) or anti-rabbit IgG Alexa488 conjugated (Invitrogen). Slides were rinsed with PBS and stained with DraQ5 (BioStatus) or chromomycin A3 (Sigma-Aldrich) to visualize chromatin, according to the manufacturer's instructions. Finally, sections were analyzed using the confocal microscope Axiovert $100 \mathrm{M}$ (Carl Zeiss Inc.) imaging system and the LSM 510 software (Carl Zeiss Inc.).

\section{Western blotting}

Proteins were isolated from gastrocnemius muscles using cOmplete Lysis-M EDTA-free kit (Roche Applied Science). $25 \mu \mathrm{g}$ of total protein lysate was denatured by boiling in Laemmli buffer and separated using SDS-Page electrophoresis and then, transferred to PVDF membrane (Roche Applied Science). Membranes were blocked with $5 \%$ Blotto (BioRad)/TBS for $1 \mathrm{~h}$ and incubated with primary antibodies diluted 1:2000 in 5\% Blotto (BioRad)/ TBS, at $4{ }^{\circ} \mathrm{C}$, overnight, followed by secondary antibodies diluted 1:20,000, at room temperature, for $2 \mathrm{~h}$. Protein bands were visualized using SuperSignal West Pico Chemiluminescent Substrate (Thermo Scientific) and exposed to chemiluminescence positive film (Amersham Hyperfilm ECL, GE Healthcare). The following primary antibodies were used: rabbit polyclonal anti-CD68 (Abcam), mouse monoclonal anti-CD163 (AbD Serotec), mouse anti-tubulin (Sigma Aldrich). Secondary antibodies used were: peroxidase-conjugate rabbit anti-mouse $\operatorname{IgG}$ (Sigma-Aldrich), peroxidase-conjugate goat anti-rabbit IgG (Sigma-Aldrich). Results were analyzed with Gel $\mathrm{Doc}^{\mathrm{TM}} \mathrm{XR}+$ System using Image Lab software (BioRad).

All experiments were performed 2-10 times (biological repeats). Results were shown as mean or median, and standard or mean deviations were presented. $t$ test was performed for statistical analysis.

\section{Results}

\section{Skeletal muscle regeneration of BALB/c and SCID mice}

The regenerating gastrocnemius muscles of $\mathrm{BALB} / \mathrm{c}$ and SCID mice were analyzed approximately $1 \mathrm{~h}$ (day 0 ) and at day 1-7, as well 30 days post injury. As a control we used intact muscles of both strains of mice. Results of this analysis showed that the mean mass of regenerating SCID mouse muscles $(n=5)$ was lower than that of $B A L B / c$ muscles $(n=3)$ (Fig. 1a). However, the differences between muscle mass of BALB/c and SCID mice were not statistically significant for either intact muscles or those analyzed at day 0-7 and day 30 of regeneration.

The number of mononucleated cells isolated from intact muscles of BALB/c $(n=4)$ and SCID $(n=2)$ mice was similar (Fig. 1b). During first days of regeneration (1-5) the number of cells isolated from the SCID mice muscles was lower as compared to BALB/c muscles (Fig. 1b). However, differences were statistically significant only at day 1 and 3 of regeneration ( $t$ test, $\mathrm{p}=0.05$ and 0.04 , respectively). 
Fig. $1 \mathrm{BALB} / \mathrm{c}$ and SCID mice gastrocnemius muscle regeneration. a The muscle weight. b The number of cells isolated from the muscles. Results were shown as means and standard deviations. Statistically significant differences were marked with asterisk ( $t$ test, $\mathrm{p}<0,05)$. INintact muscle, day $0-1 \mathrm{~h}$ after injury, day $1-7$ and 30 of regeneration
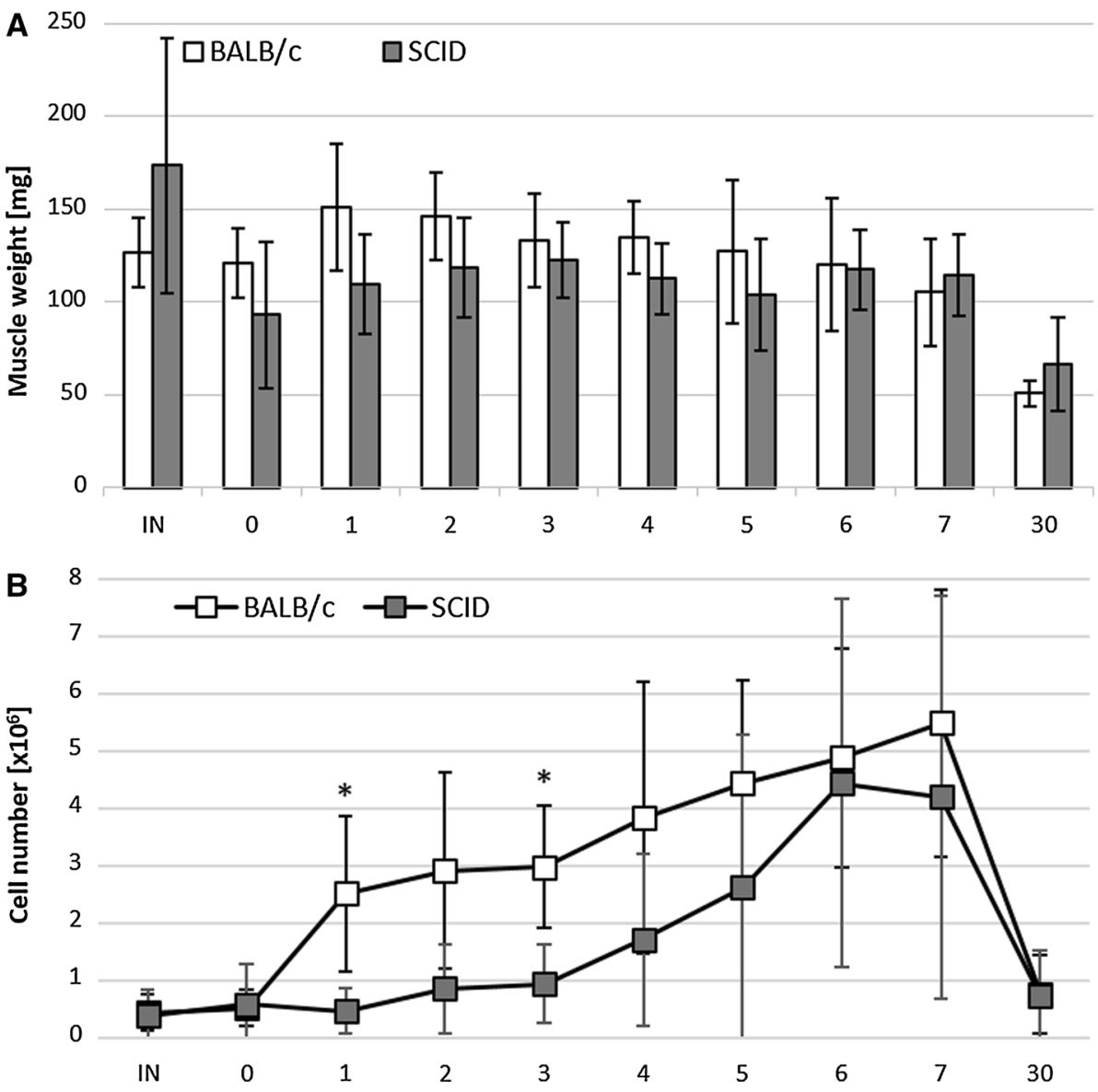

Histological analysis of regenerating muscles did not showed significant differences between BALB/c and SCID mice muscles regeneration (Fig. 2a). At day 1 of regeneration the influx of mononuclear cells and degenerating muscle fibers were characteristic for muscles of both mouse strains. Moreover, more mononucleated cells were detected in $\mathrm{BALB} / \mathrm{c}$ mice muscle at day 1 of regeneration. The number of mononucleated cells was significantly higher in BALB/c than in SCID mouse muscles $(t$ test, $\mathrm{p}=0.014, \mathrm{BALB} / \mathrm{c}$ mouse muscle $\mathrm{n}=10$, SCID mice muscles $n=5$ ) (Fig. 2b). At day 4 post injury formation of small myotubes and new muscle fibers with centrally located nuclei were noted (Fig. 2a). The new muscle fibers, with centrally located nuclei and larger diameter, were observed at day 7. However, no statistically significant differences between BALB/c and SCID mice muscle fibers diameters at day 7 and 30 of regeneration were detected ( $t$ test, $\mathrm{n}=3$ ) (Fig. 2c). At day 30 the regeneration was completed, although, immature muscle fibers with centrally located nuclei were still detectable (Fig. 2b). Moreover, at day 30 of regeneration the lower level of fibrosis was observed in $\mathrm{BALB} / \mathrm{c}$ mice muscles, as compared with SCID. The area of connective tissue was significantly lower in BALB/c than SCID mice muscles at day 30 of regeneration ( $t$ test, $\mathrm{p}=0.006, \mathrm{BALB} / \mathrm{c}$ mice muscle $\mathrm{n}=4$, SCID mice muscles $\mathrm{n}=7$ ) (Fig. 2d).

\section{Participation of CD14+ and CD45+ cells in muscle regeneration}

To follow the progress of inflammation in regenerating muscles of $\mathrm{BALB} / \mathrm{c}$ and SCID mice we analyzed the number of macrophages (CD14+/CD45+) and hematopoietic cells (CD14-/CD45+ cells), i.e. granulocytes, T-cells, B-cells, thrombocytes, but not erythrocytes, in intact muscle at $1 \mathrm{~h}$ (day 0 ) and at day $1-7$, as well as day 30 after injury $(n=3)$ (Fig. 3$)$. The number of macrophages (CD14+/CD45+ cells) was similar in samples obtained from intact muscles of BALB/c and SCID mice. Analysis of cells isolated from BALB/c muscles showed that between days 1 and 7 post injury the number of CD14+/CD45+ cells slightly increased. In SCID mice muscles, analyzed $1 \mathrm{~h}$ after the injury, the number of CD14+/CD45+ cells was higher than in intact muscle. The number of $\mathrm{CD} 14+/ \mathrm{CD} 45+$ cells was significantly higher in SCID mice muscle than BALB/c mice muscle at day 0 of regeneration $(\mathrm{p}=0.05)$. Then, at day 1 , it decreased and increased again at day 2, 3, and 4 of in regenerating SCID 
Fig. 2 a Histological analysis of $\mathrm{BALB} / \mathrm{c}$ and SCID mice gastrocnemius muscle regeneration. Harris hematoxylin-eosin staining. Scale bar $=50 \mu \mathrm{m}$. b The number of mononucleated cells present in the muscle at day 1 and 4 of regeneration. c The myofiber diameter in intact (IN) muscle and day 7 and 30 of regeneration. d The area of connective tissue at day 7 and 30 of BALB/c and SCID mice gastrocnemius muscle regeneration. Results were shown as means and standard deviations. Statistically significant differences were marked with asterisk ( $t$ test, $\mathrm{p}<0,05)$
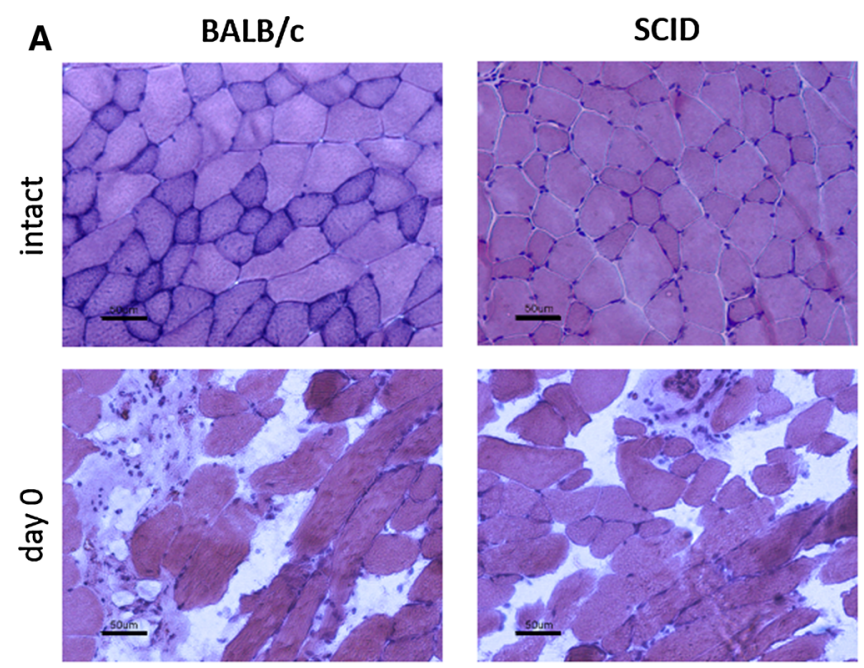

\section{B}
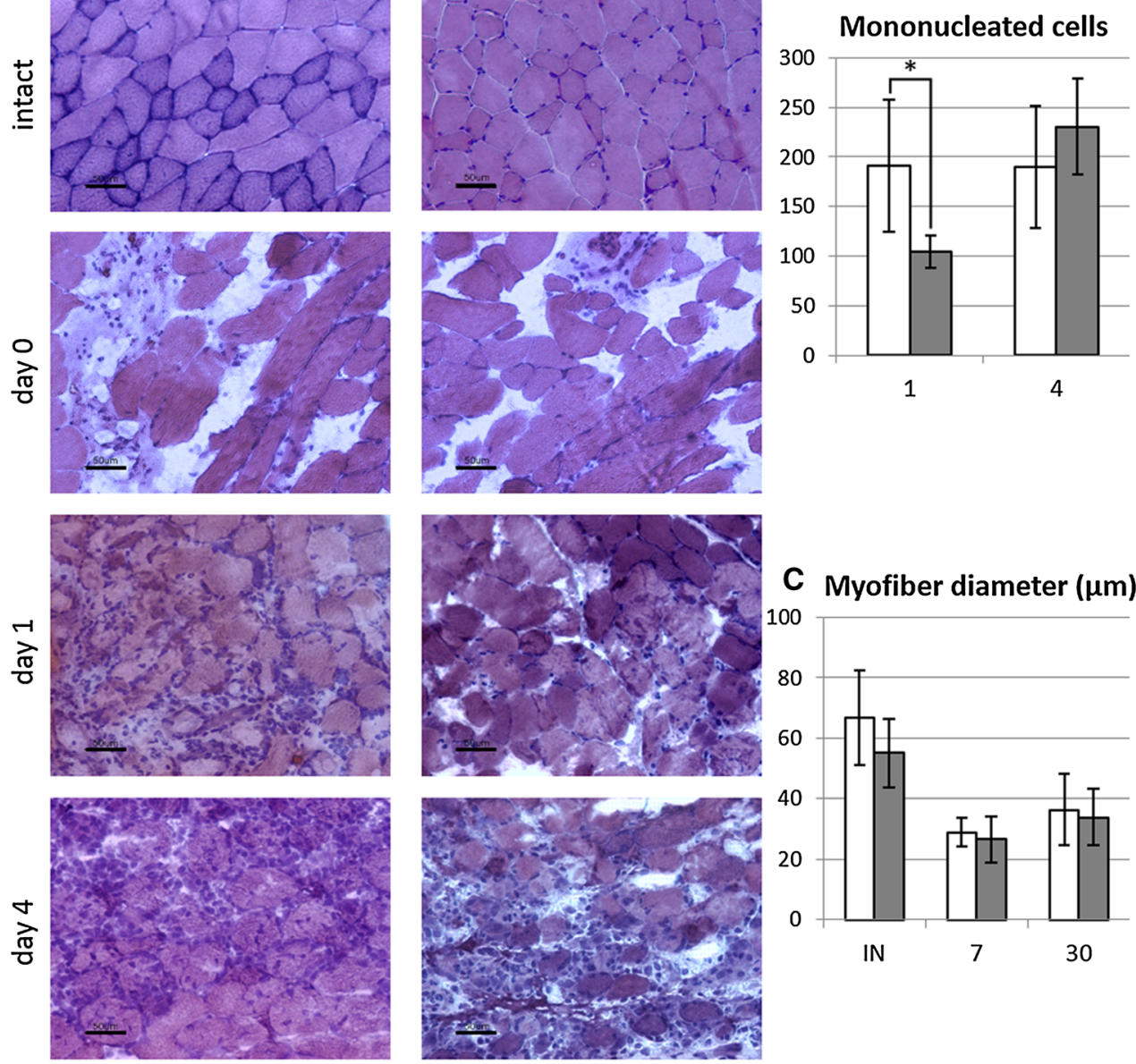

\section{Myofiber diameter $(\mu \mathrm{m})$}

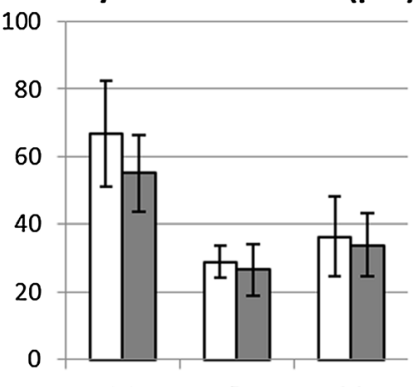

IN

30
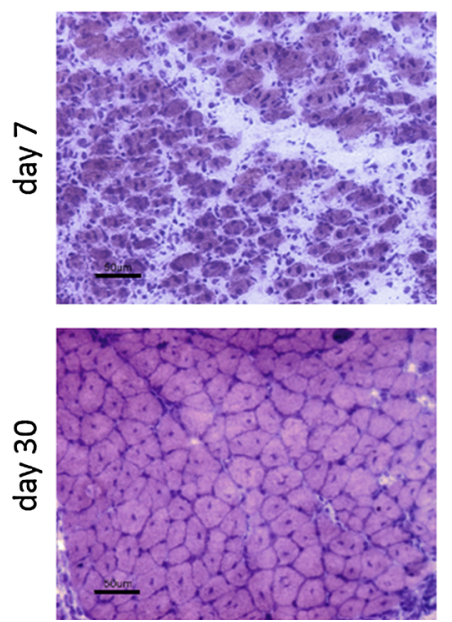

D Connective tissue (\%)

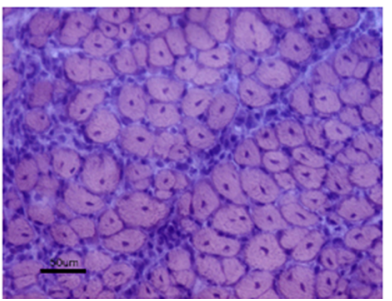

$\square B A L B / c \quad \square S C I D$

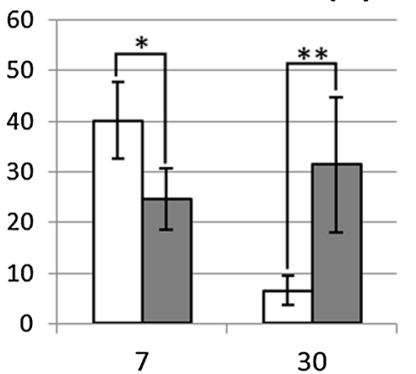

mouse muscles regeneration. At day 5 the decrease in CD14+/CD45+ cells number was observed, and it was significantly lower than in $\mathrm{BALB} / \mathrm{c}$ mice muscle $(\mathrm{p}=0.01)$. We noticed higher number of CD14+/CD45+ cells at day 6 and 7 in regenerating muscles of SCID mice. At day 30 of regeneration the number of CD14+/CD45+ cells was comparable with that observed in intact muscles. Thus, changes in macrophages level during SCID mice muscles regeneration were significant, while the changes in $\mathrm{BALB} / \mathrm{c}$ mice muscles were less pronounced.

The number of other hematopoietic cells, i.e. CD14-/ $\mathrm{CD} 45+$ increased during first $24 \mathrm{~h}$ and the highest level of 

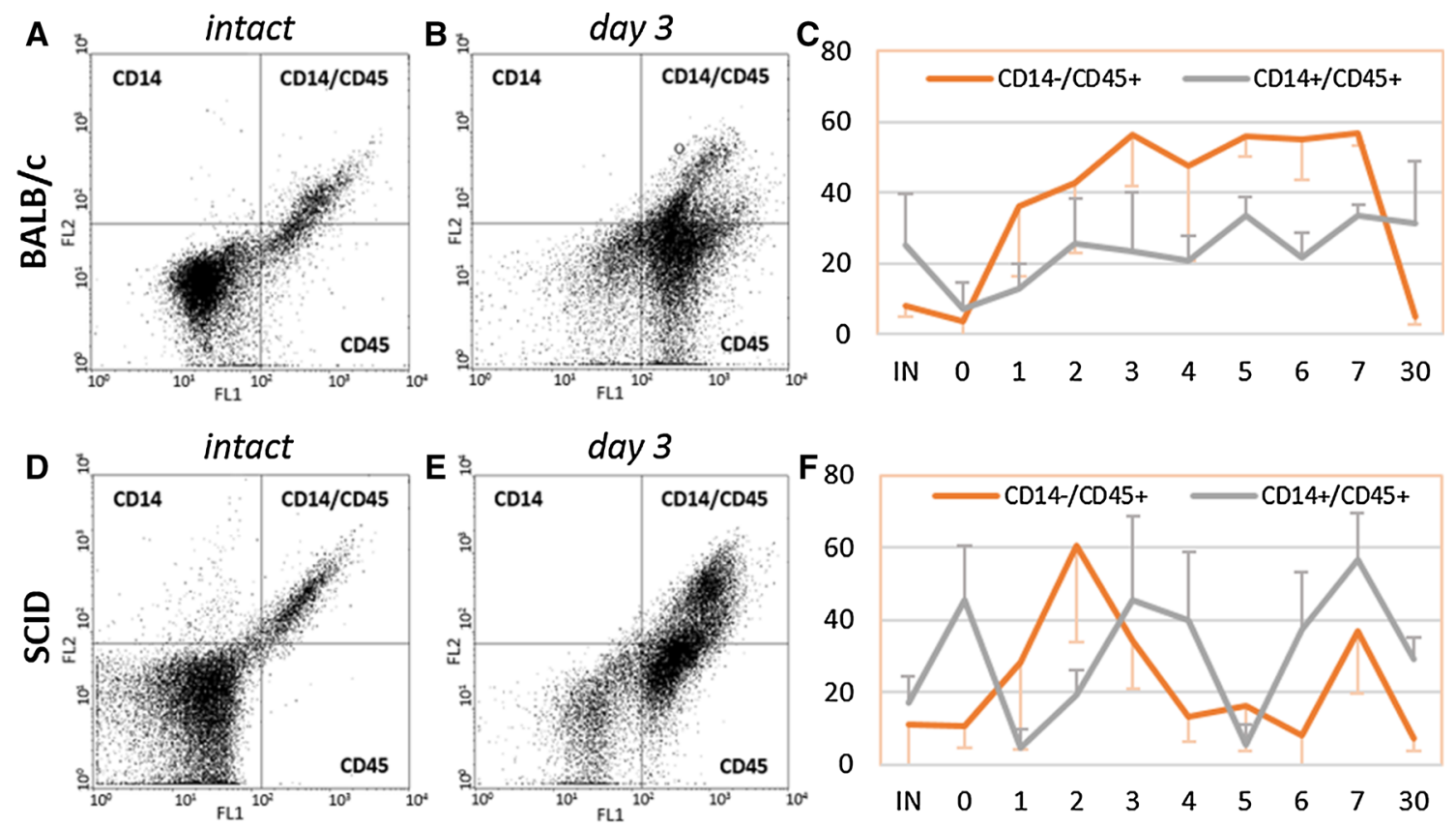

Fig. 3 Analysis of CD14+/CD45+ and CD14-/CD45+ cells isolated from regenerating gastrocnemius muscle of BALB/c and SCID mice. a FACS analysis of cells isolated from intact BALB/c mouse muscle. b FACS analysis of cells isolated from BALB/c mouse muscle at day 3 of regeneration. $\mathbf{c}$ The proportion of CD14+/CD45+ and CD14-/CD45+ cells within the cells isolated from regenerating $\mathrm{BALB} / \mathrm{c}$ mouse muscle. d FACS analysis of cells isolated from intact

these cells was observed at day 3 of BALB/c mice muscle regeneration. The number of cells was high also at day 4-7 and decreased to the levels observed in intact muscles of BALB/c mice by 30 day after injury. In case of SCID mice the number of CD14-/CD45+ cells increased slower as compared to BALB/c mice muscles. The highest number of CD14-/CD45 + cells was noticed at day 2 of regeneration, then decreased and was significantly lower than in BALB/c mice muscles analyzed at day 5 of regeneration $(p=0.02)$. Subsequent slight peak of CD14-/CD45+ cells was observed in SCID mice muscles at day 7 of regeneration. Moreover, our FACS analysis were confirmed by immunolocalization of $\mathrm{CD} 14+/ \mathrm{CD} 45+$ and $\mathrm{CD} 14-/$ $\mathrm{CD} 45+$ cells during regeneration of $\mathrm{BALB} / \mathrm{c}$ and SCID muscles (Fig. 4). Results of these analysis reflected almost precisely those obtained by FACS.

\section{The participation of M1 and M2 macrophages cells in muscle regeneration}

Observed differences in the level of CD14+/CD45+ between $\mathrm{BALB} / \mathrm{c}$ and SCID regenerating muscles prompted us to follow the M1 and M2 macrophage populations. Macrophages form heterogeneous population and could be divided into two groups-M1 and M2 (Barros et al. 2013;
SCID mouse muscle. e FACS analysis of cells isolated from SCID mouse muscle at day 3 of regeneration. $f$ The proportion of $\mathrm{CD} 14+/$ $\mathrm{CD} 45+$ and CD14-/CD45+ cells within the cells isolated from regenerating SCID mouse muscle. Results were shown as medians and mean deviations. IN-intact muscle, day $0-1 \mathrm{~h}$ after injury, day $1-7$ and 30 of regeneration

Rőszer 2015). M1 macrophages are characterized by a proinflammatory phenotype, while M2 macrophages play regulatory functions in tissue repair. In our study M1 macrophages were identified on the basis of CD68 expression and M2 macrophages on the basis of CD163 presence. In both SCID and BALB/c mice muscles, as shown directly by immunolocalization of CD68 marker (Fig. 5a), only few M1 macrophages expressing CD68 were detected in intact muscles. In BALB/c mice muscles, as shown by Western blotting technique (Fig. 5b), CD68 protein was detectable starting from day 1 of regeneration and its expression was the highest at day 1 and then decreased by day 7 of regeneration. In SCID mice muscles the level of CD68 was higher than in BALB/c mice muscles at day 3-7 of regeneration (Fig. 5b). The level of CD68 increased by day 3 of SCID mice muscle regeneration, then at day 4 decreased and did not changed until day 7. Interestingly, M2 macrophages were present in regenerating $\mathrm{BALB} / \mathrm{c}$ mice muscles (Fig. 5a) but were not detected in SCID mice muscles as shown by immunolocalization (Fig. 5a) and Western blotting (Fig. 5b) of CD163. In BALB/c mice muscles the level of CD163 increased during regeneration starting from day 4 of regeneration (Fig. 5b). At day 7 of BALB/c mice muscles regeneration the level of CD163 decreased (Fig. 5b). 

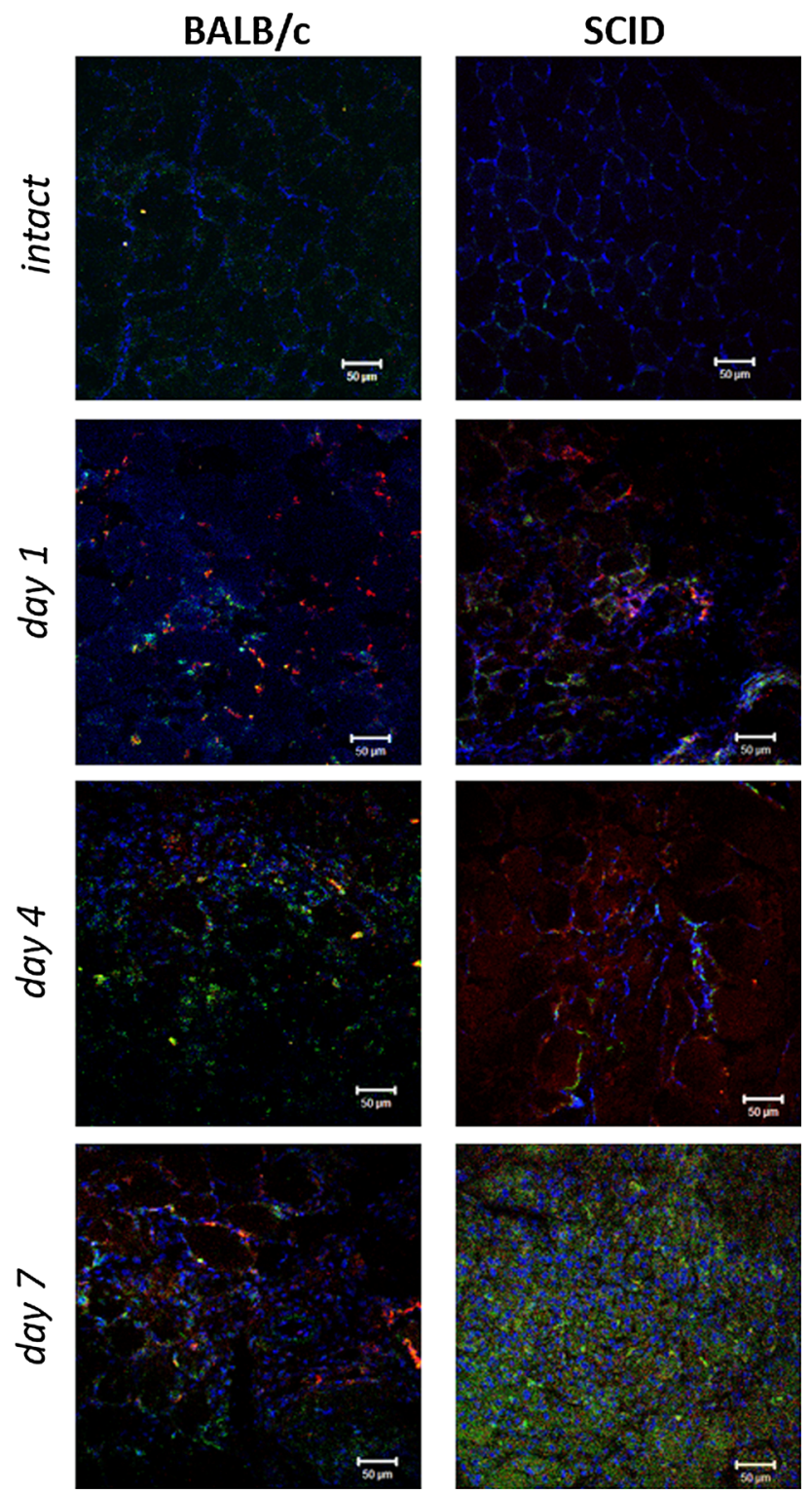

Fig. 4 Immunolocalization of CD14+, CD45+, and CD14+/CD45+ cells in intact and regenerating BALB/c and SCID mice gastrocnemius muscles. Single CD14+/CD45+ cell were observed in BALB/c muscle. At day 1 of regeneration the influx of $\mathrm{CD} 14+, \mathrm{CD} 45+$ and CD14+/CD45+ cells were noticed both in BALB/c and SCID mice gastrocnemius muscles. A large number of CD45+ and some CD14+ and $\mathrm{CD} 14+/ \mathrm{CD} 45+$ were present in BALB/c muscle at day 4 and 7 of regeneration. The SCID muscles were characterized first by decrease of inflammatory cells number (day 4) and then increase of their amount (day 7). CD14+ (red), CD45+ (green), and CD14+l $\mathrm{CD} 45+$ (yellow). Scale bar $=50 \mu \mathrm{m}$. (Color figure online)

\section{Discussion}

SCID mice are widely used in studies investigating myogenic potential of stem cells after transplantation into regenerating muscles (Arpke et al. 2013; Brzoska et al. 2006; Dellavalle et al. 2007; Grabowska et al. 2012, 2013;
Morosetti et al. 2010). However, these mice could differ from other strains in the progression of muscle repair. In fact, differences in inflammatory and muscle regeneration processes were previously observed between mice of different genetic backgrounds (Lagrota-Candido et al. 2010). For example, regenerating muscles of athymic BALB/c nude (nu/nu) mice, lacking $\mathrm{T}$ lymphocytes, are characterized by higher collagen deposition than in muscles of C57BL/6 mice (Lagrota-Candido et al. 2010). It was observed that wild type $\mathrm{BALB} / \mathrm{c}$ mice, i.e. producing $\mathrm{T}$ cells, are characterized by higher collagen deposition as compared to C57BL/6 mice (Lagrota-Candido et al. 2010). Thus, in this case fibrosis depends on the genetic background, not the lack of $\mathrm{T}$ cells. On the other hand, the absence of $\mathrm{T}$ and $\mathrm{B}$ lymphocytes in dysferlin deficient mice (animal model of dysferlinopathy) was shown to improve the skeletal muscle regeneration (Farini et al. 2012). Also dystrophic SCID/mdx mice developed much less diaphragm fibrosis than mdx mice (Farini et al. 2007). The same phenomenon was observed in $\mathrm{nu} / \mathrm{nu} / \mathrm{mdx}$ mice (Morrison et al. 2000). In our study, we compared SCID mice of the same genetic background as BALB/c mice. Thus, the fact that we noticed the higher level of fibrosis during regeneration of SCID mice muscles could be explained by the lack of $\mathrm{T}$ cells.

Immunodeficiency was previously shown to impact the histology of regenerating muscles. For example, more fibers with centrally positioned nuclei, i.e. not fully matured ones, were noticed in athymic BALB/c nude (nu/ nu) mice than in $\mathrm{C} 57 \mathrm{BL} / 6$ or BALB/c mice (LagrotaCandido et al. 2010). Thus, the regeneration of BALB/c nude mice was delayed. Our studies showed that although $\mathrm{T}$ cell-mediated response was ablated in SCID mice, the muscle regeneration process was very effective and comparable to $\mathrm{BALB} / \mathrm{c}$ mice. Injured SCID mouse muscles were completely reconstructed after 30 days. Importantly, the same number of cells was isolated from the intact muscles of both SCID and BALB/c. These cells constitute an almost pure population of satellite cells (Danoviz and Yablonka-Reuveni 2012). However, we noticed differences in the number of isolated cells and mononuclear cells present in the muscle at the early stages of regeneration. Nevertheless, these differences were not vital for the muscle reconstruction.

Our studies also showed that the lack of functional $\mathrm{T}$ cells led to the changes in macrophages contribution during muscles regeneration. In $\mathrm{BALB} / \mathrm{c}$ mice the number of hematopoietic cells that were not macrophages, i.e. CD14-/CD45+, increased during first $24 \mathrm{~h}$ after the injury and these cells were detectable during subsequent 7 days of muscle regeneration. Next, M1 and M2 macrophages were identified in analyzed muscles based on the presence of CD68 or CD163 marker (Robertson et al. 1990; Röszer 

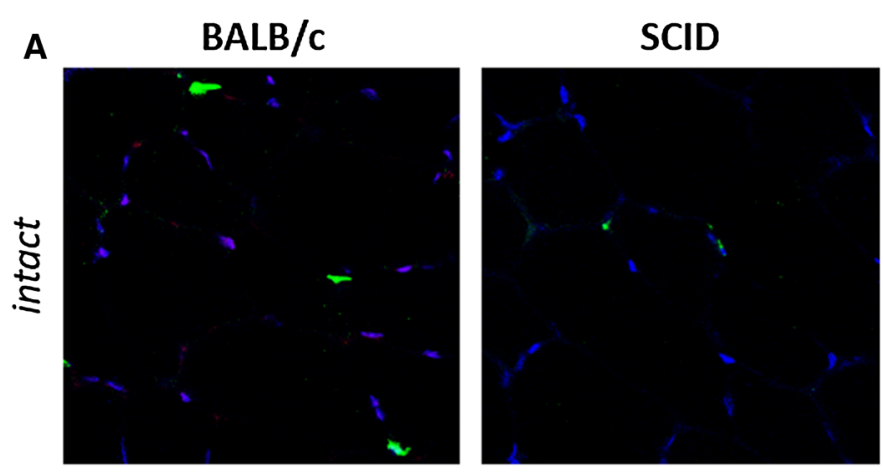

B

\section{BALB/C}

CD68

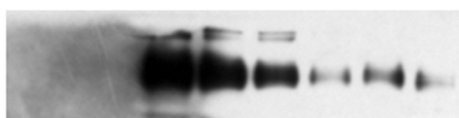

CD163
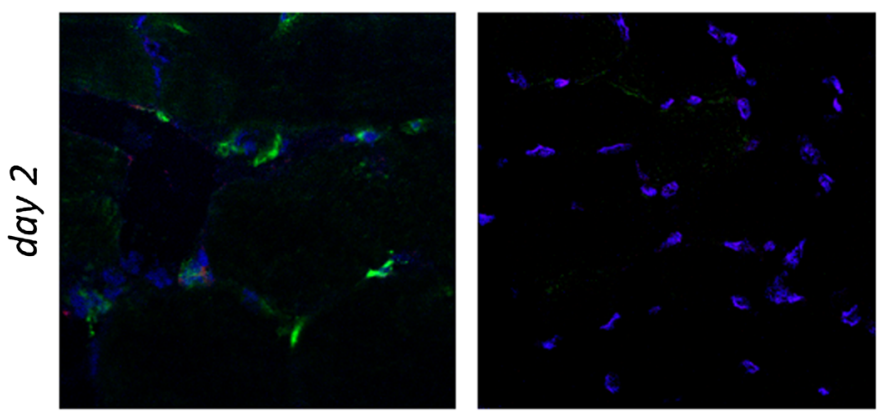

Tubulin
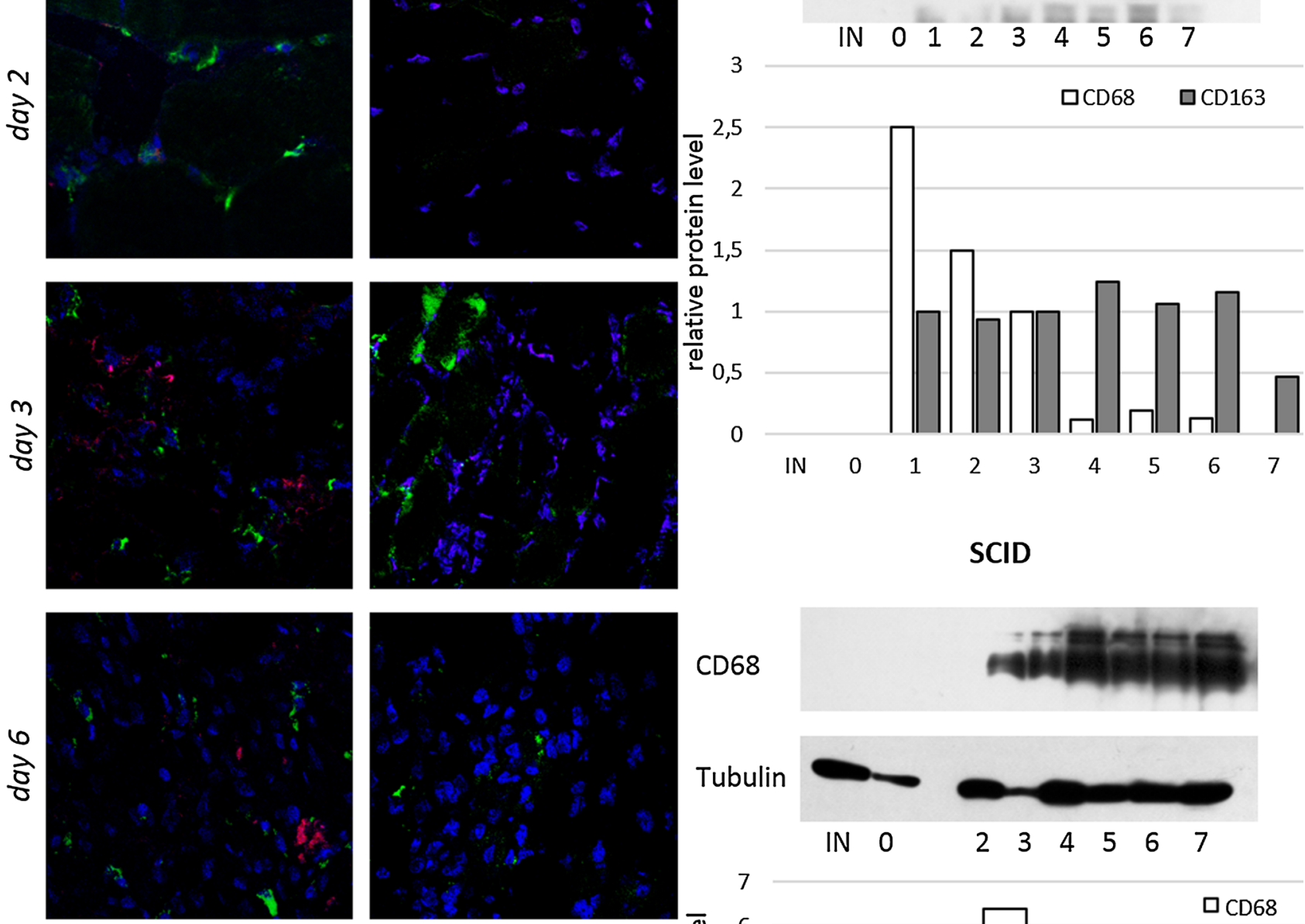

\section{CD68}
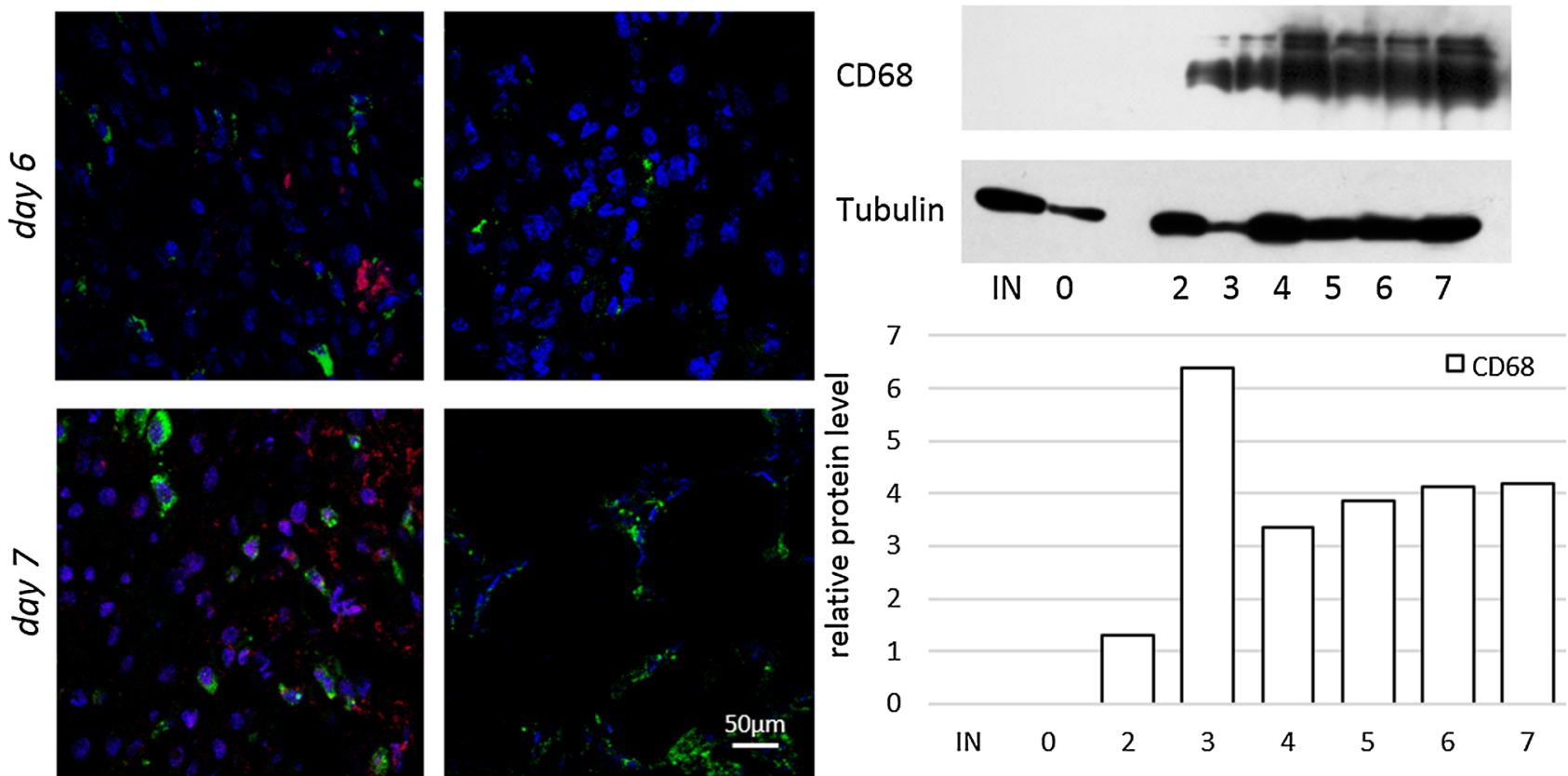
4Fig. 5 The M1 and M2 macrophages during regeneration of BALB/c and SCID mice muscles. a Immunolocalization of CD68+ (green) cells (M1 macrophages) and CD163+ (red) cells (M2 macrophages) in intact and regenerating BALB/c and SCID mice gastrocnemius muscles (day 2, 3, 6 and 7). Scale bar $=50 \mu \mathrm{m}$. Blue-nuclei. $\mathbf{b}$ The level of CD68, CD163, and tubulin protein in intact muscle (IN) and at day 0 (muscle injury) -7 of BALB/c and SCID mice gastrocnemius muscles regeneration. The chart presents relative optical densities of bands shown as a percentage of tubulin bands densities. (Color figure online)

2015). Interestingly, BALB/c and SCID mice response to muscle injury was different at the level of macrophage involvement. M1 macrophages are characterized by a proinflammatory phenotype and play important role in promotion of $\mathrm{T}$ helper 1 (Th1) immune response (Röszer 2015). M1 macrophages produce inflammatory cytokines and nitric oxide. Thus, participation of M1 macrophages in skeletal muscle regeneration was more prominent in SCID mice. Importantly, we were not able to detect anti-inflammatory M2 macrophages in regenerating SCID mice muscles. The polarization of M2 macrophages requires the presence of the Th2 immune response, that is absent in SCID mice. M2 macrophages play regulatory functions in tissue repair and remodeling (Rőszer 2015). They also promote of Th2-dependent immune response, have high phagocytotic capacity, synthesize extracellular matrix components, angiogenic and chemotactic factors (Rőszer 2015). Thus, we showed that SCID mice did not generate CD163 positive cells, i.e. M2, in the response to muscle injury. However, as we mentioned above, these differences were not translated into significant modifications in muscle regeneration.

Nevertheless, the immunodeficiency is an important factor considering cell transplantation experiments. It is essential for both xenogeneic and allogeneic transplants. The use of animals characterized by genetic deficiency is preferable to immune suppression. Two immunodeficient dystrophic models are used in transplantation studies, i.e. $\mathrm{SCID} / \mathrm{mdx}$ and mdx/nude mice. Despite ablated T-cellmediated responses in SCID and nude mice, functional natural killer (NK) cells are present. Thus, activity of NK cells must be suppressed using cyclophosphamide or specific antibodies (Brzoska et al. 2006). Another solution could be using SCID mice deficient for interleukin-2 receptor common gamma chain (IL2Rg), which are characterized with the ablation of NK cells, i.e. NOD/SCID; $\gamma$-c mice (NSG) (Traggiai et al. 2004). The NGS/mdx mice were described as mouse dystrophic model that can serve as xenogeneic transplants (Arpke et al. 2013). Summarizing, our study shows that even if the inflammation plays the crucial role in muscle regeneration in the absence of proper immunoresponse the skeletal muscle are able to effectively regenerate.
Acknowledgments This research was supported by The National Centre of Research and Development, Grant Number PBS3/A7/22/ 2015. We would like to thank all our laboratory colleagues for their support and helpful discussions.

Open Access This article is distributed under the terms of the Creative Commons Attribution 4.0 International License (http://crea tivecommons.org/licenses/by/4.0/), which permits unrestricted use, distribution, and reproduction in any medium, provided you give appropriate credit to the original author(s) and the source, provide a link to the Creative Commons license, and indicate if changes were made.

\section{References}

Arnold L et al (2007) Inflammatory monocytes recruited after skeletal muscle injury switch into antiinflammatory macrophages to support myogenesis. J Exp Med 204:1057-1069. doi:10.1084/ jem.20070075

Arpke RW et al (2013) A new immuno-, dystrophin-deficient model, the NSG-mdx(4Cv) mouse, provides evidence for functional improvement following allogeneic satellite cell transplantation. Stem Cells 31:1611-1620. doi:10.1002/stem.1402

Barros MHM, Hauck F, Dreyer JH, Kempkes B, Niedobitek G (2013) Macrophage polarisation: an immunohistochemical approach for identifying M1 and M2 macrophages. PLoS One 8:e80908. doi:10.1371/journal.pone.0080908

Basch RS, Quito FL, Beh J, Hirst JA (1997) Growth of human hematopoietic cells in immunodeficient mice conditioned with cyclophosphamide and busulfan. Stem Cells 15:314-323

Bosma GC, Custer RP, Bosma MJ (1983) A severe combined immunodeficiency mutation in the mouse. Nature 301:527-530

Brzoska E et al (2006) Participation of stem cells from human cord blood in skeletal muscle regeneration of SCID mice. Exp Hematol 34:1262-1270. doi:10.1016/j.exphem.2006.05.009

Brzoska E, Ciemerych MA, Przewozniak M, Zimowska M (2011) Regulation of muscle stem cells activation: the role of growth factors and extracellular matrix. Vitam Horm 87:239-276. doi:10.1016/B978-0-12-386015-6.00031-7

Ciemerych MA, Archacka K, Grabowska I, Przewozniak M (2011) Cell cycle regulation during proliferation and differentiation of mammalian muscle precursor cells Results and problems in cell differentiation 53:473-527. doi:10.1007/978-3-642-19065-0_20

Danoviz ME, Yablonka-Reuveni Z (2012) Skeletal muscle satellite cells: background and methods for isolation and analysis in a primary culture system. Methods Mol Biol 798:21-52. doi:10. 1007/978-1-61779-343-1_2

Dellavalle A et al (2007) Pericytes of human skeletal muscle are myogenic precursors distinct from satellite cells. Nat Cell Biol 9:255-267

Deng B, Wehling-Henricks M, Villalta SA, Wang Y, Tidball JG (2012) IL-10 triggers changes in macrophage phenotype that promote muscle growth and regeneration. J Immunol 189:3669-3680. doi:10.4049/jimmunol.1103180

Farini A et al (2007) T and B lymphocyte depletion has a marked effect on the fibrosis of dystrophic skeletal muscles in the SCID/ mdx mouse. J Pathol 213:229-238. doi:10.1002/path.2213

Farini A et al (2012) Absence of T and B lymphocytes modulates dystrophic features in dysferlin deficient animal model. Exp Cell Res 318:1160-1174. doi:10.1016/j.yexcr.2012.03.010

Grabowska I et al (2012) Restricted myogenic potential of mesenchymal stromal cells isolated from umbilical cord. Cell Transplant 21:1711-1726. doi:10.3727/096368912X640493 
Grabowska I et al (2013) Myogenic potential of mesenchymal stem cells - the case of adhesive fraction of human umbilical cord blood cells. Curr Stem Cell Res Ther 8:82-90

Grounds MD, McGeachie JK (1987) A model of myogenesis in vivo, derived from detailed autoradiographic studies of regenerating skeletal muscle, challenges the concept of quantal mitosis. Cell Tissue Res 250:563-569

Kharraz Y, Guerra J, Mann CJ, Serrano AL, Munoz-Canoves P (2013) Macrophage plasticity and the role of inflammation in skeletal muscle repair. Mediat Inflamm 2013:491497. doi:10. 1155/2013/491497

Lagrota-Candido $\mathrm{J}$ et al (2010) Characteristic pattern of skeletal muscle remodelling in different mouse strains. Int J Exp Pathol 91:522-529. doi:10.1111/j.1365-2613.2010.00737.x

Lockhart NC, Brooks SV (2008) Neutrophil accumulation following passive stretches contributes to adaptations that reduce contraction-induced skeletal muscle injury in mice. J Appl Physiol (1985) 104:1109-1115. doi:10.1152/japplphysiol.00850.2007

Mann CJ, Perdiguero E, Kharraz Y, Aguilar S, Pessina P, Serrano AL, Munoz-Canoves P (2011) Aberrant repair and fibrosis development in skeletal muscle. Skelet Muscle 1:21. doi:10.1186/20445040-1-21

Montarras D, L'Honore A, Buckingham M (2013) Lying low but ready for action: the quiescent muscle satellite cell. FEBS J 280:4036-4050. doi:10.1111/febs. 12372

Morosetti R et al (2010) Mesoangioblasts from facioscapulohumeral muscular dystrophy display in vivo a variable myogenic ability predictable by their in vitro behavior. Cell Transplant. doi:10. 3727/096368910X546571

Morrison J, Lu QL, Pastoret C, Partridge T, Bou-Gharios G (2000) T-cell-dependent fibrosis in the $\mathrm{mdx}$ dystrophic mouse. Lab Investig J Tech Methods Pathol 80:881-891

Pizza FX, McLoughlin TJ, McGregor SJ, Calomeni EP, Gunning WT (2001) Neutrophils injure cultured skeletal myotubes. Am J Physiol Cell Physiol 281:C335-C341

Renz JF, Lin Z, de Roos M, Dalal AA, Ascher NL (1996) SCID mouse as a model for transplantation studies. J Surg Res 65:34-41. doi:10.1006/jsre.1996.0340

Robertson TA, Grounds MD, Mitchell CA, Papadimitriou JM (1990) Fusion between myogenic cells in vivo: an ultrastructural study in regenerating murine skeletal muscle. $J$ Struct Biol 105:170-182
Robertson TA, Papadimitriou JM, Grounds MD (1993) Fusion of myogenic cells to the newly sealed region of damaged myofibres in skeletal muscle regeneration. Neuropathol Appl Neurobiol $19: 350-358$

Rőszer T (2015) Understanding the mysterious M2 macrophage through activation markers and effector mechanisms. Mediat Inflamm 2015:16. doi:10.1155/2015/816460

Scharner J, Zammit PS (2011) The muscle satellite cell at 50: the formative years. Skelet Muscle 1:28. doi:10.1186/2044-5040-128

Serrano AL, Mann CJ, Vidal B, Ardite E, Perdiguero E, MunozCanoves P (2011) Cellular and molecular mechanisms regulating fibrosis in skeletal muscle repair and disease. Curr Top Dev Biol 96:167-201. doi:10.1016/B978-0-12-385940-2.00007-3

Tidball JG (2005) Inflammatory processes in muscle injury and repair. Am J Physiol Regul Integr Comp Physiol 288:R345R353

Tidball JG, Villalta SA (2010) Regulatory interactions between muscle and the immune system during muscle regeneration. Am J Physiol Regul Integr Comp Physiol 298:R1173-R1187. doi:10. 1152/ajpregu.00735.2009

Traggiai E, Chicha L, Mazzucchelli L, Bronz L, Piffaretti JC, Lanzavecchia A, Manz MG (2004) Development of a human adaptive immune system in cord blood cell-transplanted mice. Science 304:104-107. doi:10.1126/science.1093933

Villalta SA, Nguyen HX, Deng B, Gotoh T, Tidball JG (2009) Shifts in macrophage phenotypes and macrophage competition for arginine metabolism affect the severity of muscle pathology in muscular dystrophy. Hum Mol Genet 18:482-496. doi:10.1093/ hmg/ddn376

Vormoor J, Lapidot T, Pflumio F, Risdon G, Patterson B, Broxmeyer HE, Dick JE (1994) Immature human cord blood progenitors engraft and proliferate to high levels in severe combined immunodeficient mice. Blood 83:2489-2497

Zhang C, Li Y, Wu Y, Wang L, Wang X, Du J (2013) Interleukin-6/ signal transducer and activator of transcription 3 (STAT3) pathway is essential for macrophage infiltration and myoblast proliferation during muscle regeneration. J Biol Chem 288:1489-1499. doi:10.1074/jbc.M112.419788 